\title{
Effect of Ultrasound on the Activity of Mushroom (Agaricus bisporous) Polyphenol Oxidase and Observation of Structural Changes Using Time-resolved Fluorescence
}

\author{
Konstantina Tsikrika ${ }^{1}$ (D) M. Adília Lemos ${ }^{1} \cdot$ Boon-Seang Chu ${ }^{1} \cdot$ David H. Bremner ${ }^{1} \cdot$ Graham Hungerford $^{2}$
}

Received: 26 July 2021 / Accepted: 31 January 2022 / Published online: 11 February 2022

(c) The Author(s) 2022

\begin{abstract}
Polyphenol oxidase (PPO) is an enzyme associated with the browning process that can occur from mechanical injury and postharvest storage. Thus, its inactivation to inhibit this process is of great interest to the food industry. Recently a nonthermal technology, high frequency ultrasound (100-1 MHz), has found usage in this aspect. In this work, the application of high-frequency $(378 \mathrm{kHz}, 583 \mathrm{kHz}, 1144 \mathrm{kHz}$, and $1175 \mathrm{kHz})$ and low frequency $(20 \mathrm{kHz})$ treatment on a PPO extract (from mushrooms) by monitoring the residual enzymatic activity is described. A control thermal treatment at $40{ }^{\circ} \mathrm{C}$ was also performed for comparison purposes. High-frequency inactivation data fitted well using the Weibull model, whereas those obtained upon low frequency followed first-order kinetics. The inactivation rate constant obtained ranged from 0.0054 $\left(20 \mathrm{kHz}\right.$ ) to $0.028 \mathrm{~min}^{-1}$ (at $583 \mathrm{kHz}$ ). To elucidate changes in the enzyme structure time-resolved spectroscopy of a commercial PPO enzyme model was employed. Results indicated that ultrasound-induced structural changes in PPO, in keeping with the activity behaviour upon sonication.
\end{abstract}

Keywords Polyphenol oxidase · Decay associated spectra $\cdot$ Enzyme inactivation · Fluorescence lifetime $\cdot$ Weibull model · High frequency ultrasound

\section{Introduction}

Polyphenol oxidase (PPO; EC 1.14.18.1) is a copper-containing enzyme commonly found in fresh fruit and vegetables, where it is associated with a postharvest browning process (Cheng et al., 2013). It results from mechanical injury, storage, or processing procedures (Fortea et al., 2009). The reaction involves the oxidation of a monophenol and/or an ortho-diphenol into their corresponding ortho-quinone derivatives and is catalysed by PPO (Ismaya et al., 2011). The o-quinones can undergo further polymerisation to yield undesirable brown pigments in the presence of oxygen. Enzymatic browning is associated with off-flavours and can make a significant contribution to loss in nutritional

Konstantina Tsikrika

kontsikrika@gmail.com

1 Division of Engineering and Food Science, School of Applied Sciences, Abertay University, Bell Street, Dundee DD1 1HG, UK

2 HORIBA Jobin-Yvon IBH Ltd, 133 Finnieston Street, Glasgow G3 8HB, UK quality, leading to a decrease in the market value of the food and food products. Therefore, the inhibition of enzymatic browning is a requirement in the food industry (Cheng et al., 2013). Thermal processes tend to be the most common techniques employed for enzyme inactivation. However, heat treatments can result in the development of undesirable flavours and deterioration of functional properties of food products, as well as nutrient loss (Morales-de la Peña et al., 2019; Shinwari \& Rao, 2018). The demand for fresh-like fruit and vegetable products is continually rising, promoting the use of novel nonthermal food technologies for PPO inactivation in foods, namely ultrasound (US), high-pressure processing, and pulsed electric fields (Silva \& Sulaiman, 2018; Shinwari \& Rao, 2021). Ultrasound technology, in particular, has been investigated as a green milder food processing technique, entailing energy and water saving with reduced carbon and water footprint and relatively low chemical and physical hazards, to provide a full or partial alternative to conventional heat treatment (Chemat et al., 2011, 2017).

The application of ultrasound to inactivate PPO is an active area of study. However, most studies make use of low-frequency ultrasound $(20-40 \mathrm{kHz})$. Recently, a significant decrease in PPO activity in quince juice (Iqbal 
et al., 2020) and bayberry juice (Cao et al., 2018) after sonication at $20 \mathrm{kHz}$ was reported, and similar results were observed by Saeeduddin et al. (2015) for PPO in pear juice. The effect of low frequency/high power ultrasound $(20 \mathrm{kHz}, 100-500 \mathrm{~W})$ on PPO in orange juice (Zhu et al., 2019) and oriental sweet melon was examined, and PPO inactivation was only noticed when the power was above $200 \mathrm{~W}$ (Liu et al., 2017). Notably, Bi et al. (2015) found that using an ultrasound treatment at $20 \mathrm{kHz}$ increased PPO activity in the avocado puree.

Although the use of ultrasound as a means to inactivate and/or activate enzymes has been widely studied at low frequencies, the high power involved is more likely to have a detrimental effect on the properties and quality of some food products (Pingret et al., 2013). On the other hand, high frequency (low intensity) ultrasound is known to be a nondestructive and noninvasive technique to monitor and evaluate food products during their processing and storage (Bhargava et al., 2021). Hence its use in food processing is an interesting recent area of research. Tsikrika et al. (2018) investigated the effect of high-frequency ultrasound on the model system of horseradish peroxidase, where the use of a high frequency was more efficient for enzyme inactivation. Nevertheless, despite the findings of this study, there is very limited data on the effect of high-frequency ultrasound in food preservation, including the inactivation of food enzymes. In fact, there is a research void in this area which needs to be addressed. Consequently, this work aims to further investigate and compare the effectiveness of high and low-frequency ultrasound on the inactivation of PPO, considering how the process affects the enzyme structure, which will be monitored by fluorescence lifetime spectroscopy.

The presence of both tyrosine and tryptophan residues in PPO enables fluorescence spectroscopy to be used to elucidate changes in enzymatic structure. Excitation at $280 \mathrm{~nm}$ excites both of these amino acids (Lakowicz, 2006) and their proximity allows for energy transfer between the tyrosine to the tryptophan. This can result in the observed emission predominantly arising from the tryptophan residues, whose emission is more environmentally sensitive than tyrosine (Lakowicz, 2006). It is expected that any ultrasound-induced changes in the enzymatic structure may affect both the fluorophore's local environment, and their relative separations, hence changing the energy transfer efficiency. Time-resolved fluorescence, plus the determination of decay-associated spectra, is particularly useful in separating the emissions from different fluorescing species. Although it should be acknowledged that in systems containing multiple fluorophores, interpretation of results may not be simple, however relative changes in fluorescence behaviour can be indicative of structural perturbation.
The aim of this study is to investigate the effect of ultrasound treatment at low $(20 \mathrm{kHz})$ and high frequencies $(378 \mathrm{kHz}, 583 \mathrm{kHz}, 1144 \mathrm{kHz}$, and $1175 \mathrm{kHz}$ ) and different powers (10-49 $\mathrm{W})$ on the activity of PPO extracted from the chestnut mushroom. To our knowledge, this is the first time that high-frequency ultrasound has been used for the inactivation of PPO. A crude mushroom extract was used to mimic real-world conditions. The enzyme activity at different treatment times was obtained, and the kinetics were modelled. A control thermal treatment was also conducted for comparison purposes. A fluorescence study was performed to elucidate any changes in enzymatic structure, making use of commercial purified mushroom PPO to avoid the influence of any fluorescent impurities that could be present in the crude extract. Both steady-state and time-resolved fluorescence measurements were performed, and decay-associated spectra were obtained.

\section{Materials and Methods}

\section{Chemicals}

Catechol, sodium phosphate monobasic, sodium phosphate dibasic, polyvinylpolypyrrolidone (PVPP), triton X-100, tyrosinase from mushroom (EC 1.14.18.1) were purchased from Sigma-Aldrich, Gillingham, UK. All chemicals were analytical grade.

\section{Sample Preparation}

Freshly harvested chestnut mushrooms (Agaricus bisporus) were purchased from a local market in Dundee, UK. Mushrooms of commercial maturity were selected, washed thoroughly with double distilled water, and then used in order to produce the crude PPO extract. This was prepared using a modified method of Sulaiman et al. (2015a, b). Mushrooms (500 g) were mixed with a sodium phosphate buffer solution $(1 \mathrm{~L}, 0.1 \mathrm{M}$; pH 6.0) containing $4 \%(w / v)$ insoluble PVPP with the addition of $1 \%(v / v)$ triton X-100 and blended for $3 \mathrm{~min}$ in a kitchen blender. The homogenate was then centrifuged at $10,000 \mathrm{~g}$ for $30 \mathrm{~min}$ at $4{ }^{\circ} \mathrm{C}$, and the supernatant was collected. The crude PPO extract for this study was kept frozen at $-15^{\circ} \mathrm{C}$. When required, an aliquot of the frozen extract was diluted in sodium phosphate buffer with a $1: 10(v / v)$ dilution. A solution of $0.04 \mathrm{mg} / \mathrm{mL}$ of mushroom tyrosinase was prepared using sodium phosphate buffer solution $(0.1 \mathrm{M} ; \mathrm{pH}$ 6.0) for the purposes of the fluorescence experiments. 


\section{Ultrasound Treatment}

The ultrasound equipment used in these experiments was a Misonix Ultrasonic Liquid Processor operating (FB705, Fisher Scientific) at $20 \mathrm{kHz}\left(1.17 \mathrm{~cm}^{2}\right.$ surface area) or Meinhardt Ultraschlltechnik high-frequency sonicator (HM80012) with a Meinhardt Power Amplifier (M-11). The highfrequency sonicator has two transducers: a F701 transducer operating at $378 \mathrm{kHz}, 995 \mathrm{kHz}$ and $1175 \mathrm{kHz}$, and a 7712 transducer operating at $583 \mathrm{kHz}, 862 \mathrm{kHz}$, and $1144 \mathrm{kHz}$. The transducer $\left(22.05 \mathrm{~cm}^{2}\right.$ surface area) was connected to a glass reaction vessel with a cooling jacket. The power input (W) was determined by calorimetry, as described in Milne et al. (2013), while the intensities $\left(\mathrm{W} / \mathrm{cm}^{2}\right)$ were calculated by dividing the US power by the surface area of the $20 \mathrm{kHz}$ probe or that of the high-frequency transducer (Table 1).

When using the $20 \mathrm{kHz}$ sonicator, a standard volume of diluted extract $(200 \mathrm{~mL}$ ) was put into a $400 \mathrm{~mL}$ beaker (with similar dimensions and geometry to the glass reaction vessel connected to the high frequency transducer). The beaker was then placed in a $2 \mathrm{~L}$ ice bath filled with crushed ice and tap water $(400 \mathrm{~mL})$. The $20 \mathrm{kHz}$ sonicator probe was positioned, consistently, $20 \mathrm{~mm}$ from the bottom of the $400 \mathrm{~mL}$ beaker. A thermometer was also suspended in the beaker to allow the temperature to be monitored. The $20 \mathrm{kHz}$ sonicator experiments were all conducted at $35 \mathrm{~W}$ and operated on a pulse mode of $4 \mathrm{~s}$ on and $2 \mathrm{~s}$ off until 90 min of sonication were completed. Samples were removed after 10, 20, 30, 40, $50,60,75$, and 90 min of sonication and kept on ice until they were analysed. When using a high-frequency sonication, a standard volume of diluted extract $(200 \mathrm{~mL})$ was put in the reaction vessel, a thermometer was suspended in the reaction liquid, and cooling was achieved with a flow of cold water through the reactor jacket. The high-frequency sonicator was set at appropriate amplitude, depending on the specific frequency chosen (Table 1), and sonicated for $90 \mathrm{~min}$. Samples were withdrawn after 10, 20, 30, 40, 50, 60,75 , and 90 min of sonication and kept on ice until they were analysed.

\section{Thermal Treatment (Control)}

The temperature was monitored during all the sonication treatments. The initial temperature of all ultrasound experiments was $19 \pm 2{ }^{\circ} \mathrm{C}$ with a maximum of $40 \pm 3{ }^{\circ} \mathrm{C}$, hence a treatment at $40{ }^{\circ} \mathrm{C}$ was performed as a control. A $250 \mathrm{~mL}$ Duran glass bottle containing $200 \mathrm{~mL}$ of diluted extract was placed in the middle of a water bath equilibrated at $40{ }^{\circ} \mathrm{C}$. At predetermined time intervals (10, 20, 30, 40, 50, 60, 75, and $90 \mathrm{~min}$ ), samples were removed and immediately immersed in an ice bath prior to analysis.

\section{PPO Activity and Kinetics}

PPO activity (expressed as $\Delta \mathrm{A}_{420} \min ^{-1} \mathrm{~g}^{-1} \mathrm{FW}$ ) was assayed according to a modified method of Buckow et al. (2009). The diluted extract $(150 \mu \mathrm{L})$ was mixed with catechol solution ( $0.5 \mathrm{~mL} ; 0.05 \mathrm{M}$ in $0.1 \mathrm{M}$ sodium phosphate buffer, $\mathrm{pH} 6.0)$ and sodium phosphate buffer $(1.5 \mathrm{~mL} ; 0.1 \mathrm{M} \mathrm{pH} 6.0)$. Oxidation of catechol was then measured immediately at $420 \mathrm{~nm}$ and $25^{\circ} \mathrm{C}$ every $5 \mathrm{~s}$ for a total duration of $90 \mathrm{~s}$ on a UV spectrophotometer (UV-1650 PC, Shimadzu UK Ltd). The residual activity (RA) of PPO was calculated using Eq. 1, where $A_{\mathrm{t}}$ and $A_{0}$ are PPO activity after and before the treatment, respectively.

Residual activity $\%=\left(A_{t} / A_{0}\right) \times 100$

The inactivation kinetics of mushroom PPO were evaluated using the Weibull model, which accounts for the fact that the inactivation mechanism may differ amongst macromolecules. Hence the survival curve can be represented as the cumulative form of the underlying distribution of the different inactivation times (Jaramillo Sánchez et al., 2018). The Weibull model can be described by the equation below (Eq. 2):

$A_{t}=A_{0} \exp \left(-(k t)^{\gamma}\right)$

where $A_{\mathrm{t}}$ is the activity at time $t, A_{0}$ is the initial activity, $t$ is the treatment time $(\mathrm{min}), k$ is the rate constant $\left(\mathrm{min}^{-1}\right)$, and $\gamma$ is the shape parameter. This indicates the concavity
Table 1 Kinetic parameters from use of the Weibull model for the effect of ultrasound treatment on PPO extracted from mushroom

\begin{tabular}{lllll}
\hline $\begin{array}{l}\text { Conditions frequency } \\
(\mathbf{k H z})\end{array}$ & Power $\left(\mathbf{W}, \mathbf{w} / \mathbf{c m}^{\mathbf{2}}\right)$ & $\begin{array}{l}\boldsymbol{K}, \text { rate constant } \\
\times \mathbf{1 0}^{\mathbf{3}} \\
\left(\mathbf{m i n}^{-\mathbf{1}}\right)\end{array}$ & $\boldsymbol{\Gamma}$, shape parameter & Adjusted $\boldsymbol{R}^{\mathbf{2}}$ \\
\hline $\mathbf{2 0}$ & $35(29.9)$ & $5.4 \pm 1.1$ & $0.9 \pm 0.2$ & 0.980 \\
$\mathbf{3 7 8}$ & $10(0.45)$ & $9.5 \pm 5.2$ & $1.8 \pm 0.19$ & 0.997 \\
& $32(1.45)$ & $22 \pm 0.8$ & $1.8 \pm 0.06$ & 0.999 \\
& $48(2.17)$ & $23 \pm 0.7$ & $2.4 \pm 0.16$ & 0.997 \\
$\mathbf{5 8 3}$ & $34(1.54)$ & $24 \pm 2.3$ & $1.8 \pm 0.02$ & 0.999 \\
& $48(2.17)$ & $28 \pm 3.6$ & $1.7 \pm 0.05$ & 0.999 \\
$\mathbf{1 1 4 4}$ & $49(2.22)$ & $23 \pm 2.4$ & $1.9 \pm 0.04$ & 0.999 \\
$\mathbf{1 1 7 5}$ & $39(1.77)$ & $21 \pm 0.3$ & $1.4 \pm 0.2$ & 0.999 \\
\hline
\end{tabular}


$(\gamma>1$, curve forms shoulders) or convexity $(\gamma<1$, curve forms tails) of the curve. A shoulder on the curve can be indicative of PPO isoenzymes formation, which can exhibit different behaviours under ultrasound treatment. The calculations and the plots for the Weibull model were performed using Origin software.

\section{Data Analysis}

Statistical analysis was performed using a Mixed-Linear model by IBM SPSS Statistics 23. A mixed-effect model was produced with time $(\mathrm{min})$, frequency $(\mathrm{kHz})$, and power $(\mathrm{W})$ as covariates to examine any possible interaction between power, frequency, and time at each experiment. Variation between replicate samples was treated as a random factor. Linearity between the predicted values and the dependent variable (PPO RA), normality of distribution of residuals, and independence of residuals were also checked. Values presented are the mean of experiments done in triplicate and replicated 3 times $(n=9)$. The values were considered significantly different when $p<0.05$.

\section{Fluorescence Measurements}

Absorbance measurements were made using a Shimadzu UV-1800, and both steady-state and time-resolved fluorescence data were obtained using a HORIBA Scientific DeltaFlex-01-DD fluorimeter equipped with a DeltaDiode excitation source (DD-280). The spectral data are shown uncorrected and collected with a $6 \mathrm{~nm}$ bandpass. The timeresolved data were analysed globally as a sum of exponentials (see Eq. 3), linking common lifetimes to all of the decays, using reconvolution analysis (Birch \& Imhof, 1991). A value for the average lifetime was also returned.

The fluorescence decay is of the form

$I(t)=\sum_{i=1}^{n} \alpha_{i} \exp \left(-{ }^{t} / \tau_{i}\right)$

With the contribution of each lifetime represented by the normalised pre-exponential ( $\alpha$, see Eq. 4$)$ to indicate the relative "concentration" of that fluorescing species

$$
\alpha_{i}=\frac{\alpha_{i}}{\sum_{i=1}^{n} \alpha_{i}}
$$

The average lifetime was obtained from

$$
\tau_{\text {ave }}=\sum_{i=1}^{n} \alpha_{i} \tau_{i}
$$

Decay-associated spectra were calculated from the global analysis module within the EzTime software package from a TRES (time-resolved emission spectrum) measurement. Decay histograms were obtained for equal data collection times at $5 \mathrm{~nm}$ intervals. The data were analysed as the sum of a four exponential decay, with one lifetime fixed to half the width of a time bin (13 ps) to account for scattering and/ or lifetimes beyond the time resolution of the equipment ( $\tau \geq \sim 25 \mathrm{ps)}$ (Lemos \& Hungerford, 2013). The number of exponentials chosen was the minimum required to obtain a satisfactory fit; judged in terms of weighted residuals and goodness of fit parameter (chi-squared value).

\section{Results and Discussion}

\section{PPO Inactivation Kinetics upon Ultrasound Treatment}

The effect of low and high ultrasound frequencies and different acoustic powers $(10-49 \mathrm{~W})$ on the enzymatic activity of PPO extract was investigated, and the residual PPO activity was ascertained at various times throughout the treatment. As with a previous study (Tsikrika et al., 2018), a thermal treatment at $40{ }^{\circ} \mathrm{C}$ was also conducted as a control. It should be noted that all experiments resulted in significant $(p<0.05)$ decrease in enzyme activity and that enzyme reactivation did not occur after any treatment. Furthermore, statistical analysis to determine any interactions between the different experimental conditions were performed and are given in the Supporting Information. This uncovered a significant interaction between time $*$ frequency $(F(1694)=208$; $p<0.001)$, time * power $(F(1695)=245 ; p<0.001)$, and also time $*$ frequency $*$ power $(F(1694)=181 ; p<0.001)$. However no significant interaction between frequency $*$ power $(F(12,158)=1.3 ; p=0.563)$ was found. The statistically significant interaction amongst treatment duration (time), frequency, and power indicate that the rate of inactivation of PPO is not the same for the different treatments studied. There was also a significant effect of time $(p=0)$, which is difficult to interpret because of the presence of the interaction, whereas frequency $(p=0.651)$ and power $(p=0.576)$ did not have a significant effect on enzyme residual activity.

PPO inactivation kinetics can be described by various models; the most common is the first-order kinetics model (Cheng et al., 2013; Sulaiman et al., 2015a, b). However, biphasic behaviour has also been reported (Ludikhuyze et al., 2003). Nevertheless, plants naturally contain isoenzymes, i.e., several forms of the same type of enzyme which catalyse the same reaction but may exhibit different physicochemical and thermal resistance properties. Hence, in order to represent these complex mechanisms of enzyme inactivation, the more realistic and flexible approach using the Weibull model was employed. This model has been used to describe enzyme inactivation by 
various nonthermal processes such as ultrasound (Rojas et al., 2017), pulsed electric fields (Elez-Martnez et al., 2006; Giner et al., 2005; Soliva-Fortuny et al., 2006; Quintão-Teixeira et al., 2013), high hydrostatic pressure (Buckow et al., 2009), and ozonation (Jaramillo Sánchez et al., 2018). This approach was further justified as initial tests using first order and biphasic models resulted in poor fits, while the Weibull model fitted well to the data.

The inactivation kinetics curves of PPO at different frequencies and powers are shown in Fig. 1, with the corresponding fit parameters given in Table 1. It should be noted that a control experiment run for $75 \mathrm{~min}$, without the application of ultrasound and at a temperature of $40{ }^{\circ} \mathrm{C}$, produced a decrease in the residual activity to $\sim 88 \%$ of its initial value. This occurred in the first $\sim 20 \mathrm{~min}$ (see supporting information). All the data showed here exhibit larger decreases, and thus, this can be attributed to the influence of sonication rather than just a purely thermal process.
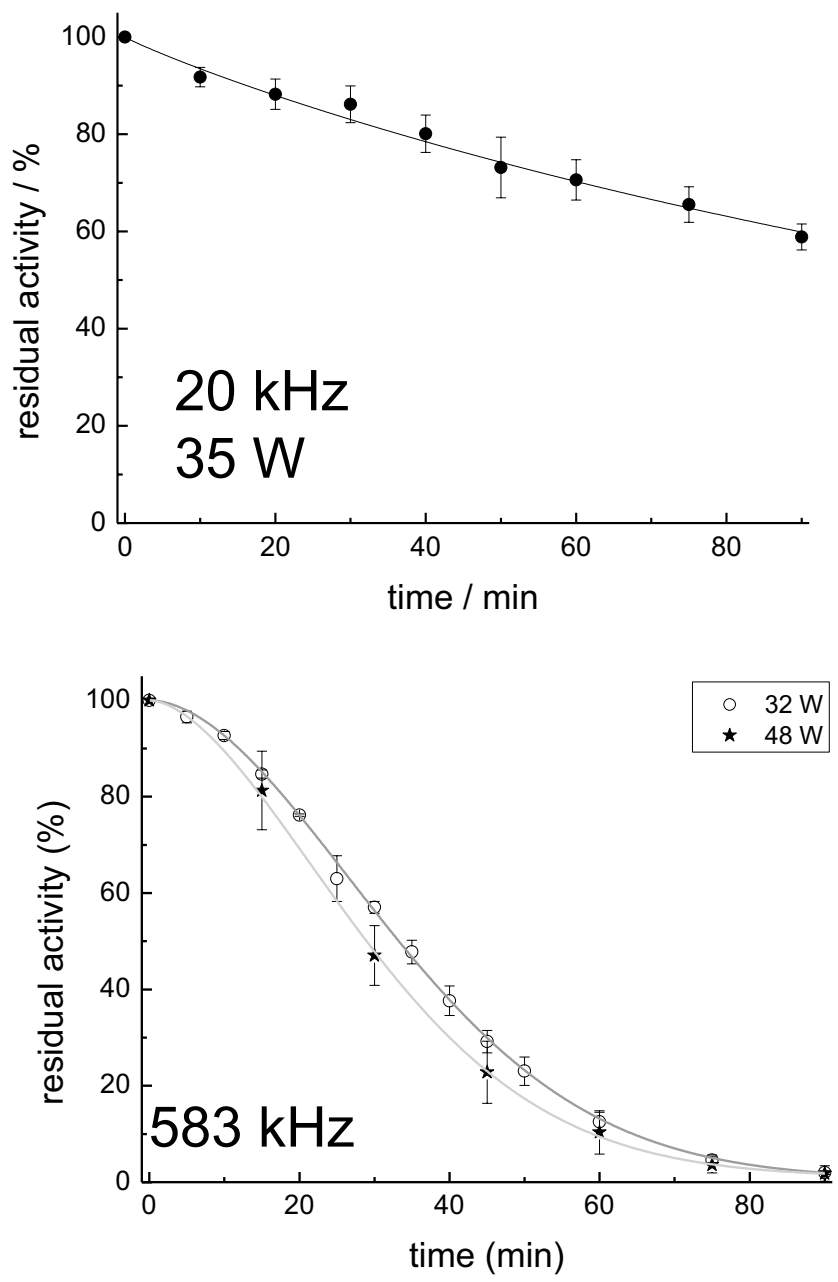

Fig. 1 Inactivation curves for PPO upon sonication at different frequencies and powers. For the higher frequencies 1144 and $1175 \mathrm{kHz}$, the powers were 49 and $39 \mathrm{~W}$, respectively. Thermal treat-
When low frequency at $20 \mathrm{kHz}$ was applied at $35 \mathrm{~W}$ (Fig. 1), the value of the shape parameter was found to be 0.9 , while the inactivation rate constant was $5.4 \times 10^{-3} \mathrm{~min}^{-1}$. This value of shape parameter is indicative that the enzyme population has a higher homogeneity i.e., more isozymes with similar stability, and subsequently with a similar critical time of inactivation. Therefore, these PPO inactivation kinetics data can also be considered to designate the presence of a first-order model, and at the end of the experiment, the residual activity was $\sim 59 \%$. This, however, is clearly not the case when considering the curve shapes of the higher frequency sonicated samples. Considering similar powers, $35 \mathrm{~W}, 32 \mathrm{~W}, 34 \mathrm{~W}$, and $39 \mathrm{~W}$ across the frequencies, $20 \mathrm{kHz}$, $378 \mathrm{kHz}, 583 \mathrm{kHz}$, and $1175 \mathrm{kHz}$, respectively, it is noticeable that the application of higher frequencies results in a much lower ( 2\% cf. 57\%) residual activity compared to the lower $(20 \mathrm{kHz})$ frequency over the same period. Also, at $378 \mathrm{kHz}$, the lower acoustic power $(10 \mathrm{~W})$ gave a higher
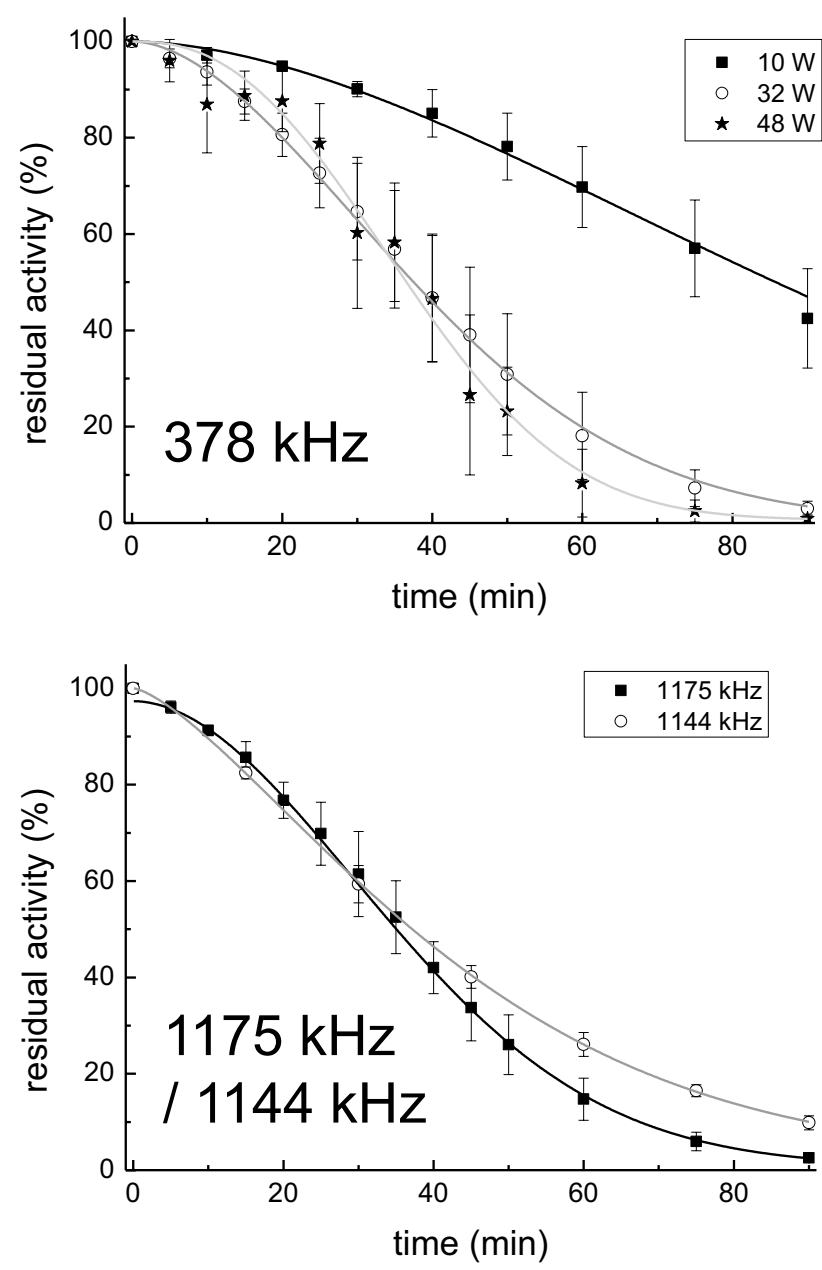

ment (Fig. S1), without sonication, gave a residual activity of $\sim 88 \%$ after $20 \mathrm{~min}$, which then remained constant. All data were fitted to a Weibull model, with the derived parameters presented in Table 1 
residual activity, with the rate constant about half of that when higher powers were used at that frequency. Here, lowfrequency ultrasound had a limited effect on enzyme activity, whereas the application of higher frequencies was more influential. The most effective conditions for PPO inactivation regarding ultrasonic treatment were 378 and $583 \mathrm{kHz}$ at $48 \mathrm{~W}$, resulting in less than $2 \%$ residual activity after $90 \mathrm{~min}$ of treatment.

The influence of low frequency $(19-25 \mathrm{kHz})$ ultrasonic treatment on PPO activity has varied widely depending on the power employed (Cao et al., 2018; Dias et al., 2014) and temperature (Saeeduddin et al., 2015). However, Abid et al. (2014) treated apple juice with ultrasound at $25 \mathrm{kHz}$ and did not notice any significant decrease in PPO residual activity, while Yu et al. (2013) reported an increase in PPO activity when treating the enzyme using an ultrasonic bath operating at $40 \mathrm{kHz}$ and $100 \mathrm{~W}$. They attributed these results to various factors, such as mass transfer because of micro-mixing, along with enzyme release caused by cell break-up. This produces biochemical reactions within cell tissues resulting in enhancement of the production of specific enzymes. Similar results were observed by Bi et al. (2015), who reported an increase in the residual activity of PPO extracted from avocado puree. However, such enzymatic behaviour was not observed in this work. These variations in PPO inactivation kinetics could be attributed to the different enzyme extraction sources, variations between crude and purified enzymes, as well as in differences in the response of the enzyme towards the various conditions studied (Cheng et al., 2013; Rojas et al., 2017). It appears that the effect of ultrasound on enzyme kinetics is enzyme specific, for instance, horseradish peroxidase treated with high-frequency ultrasound was well described by a first-order model (Tsikrika et al., 2018). The fact that we find PPO better described by the Weibull model may be explained by differences in the structure of the enzymes, including the amino acid composition and their interference with the free radicals produced during the sonication process. Similar observations were made by Illera et al. (2018) when they applied thermosonication for enzyme inactivation in cloudy apple juice. They used both the first order and Weibull model to fit the inactivation kinetics data of PPO and reported that the first-order kinetic model could result in an overprocessing for PPO inactivation.

\section{Fluorescence Monitoring of PPO to Elucidate Structural Changes upon Ultrasound Treatment}

The inactivation of enzymes by ultrasound is mainly associated with the mechanical and chemical processes that occur as a consequence of cavitation (Raviyan et al., 2005). Consequently, the secondary and tertiary structures of the enzyme are altered resulting in a loss in their biological activity (Tian et al., 2004). Liu et al. (2017) reported denaturation of purified PPO with a loss of $\alpha$-helix content, determined by circular dichroism, after low frequency/high power ultrasound treatment. They also observed alterations in the tertiary structure of sonicated samples of purified PPO, with fluorescence indicating that the fluorescent amino acids became increasingly buried and encapsulated in the protein. The position of these fluorophores is shown schematically in Fig. 2. Baltacioğlu et al. (2017) suggested that thermosonication inactivation of mushroom PPO was not due to an insignificant change in the active site, but because of a global conformation change of the enzyme. In order to gain an insight to what could be happening a time-resolved fluorescence study was performed making use of commercial mushroom PPO. A sample heat treated at $40{ }^{\circ} \mathrm{C}$ to mimic the heating effect of the ultrasound treatment was also measured without the application of ultrasound.

The steady-state spectra obtained from both the ultrasound and thermally treated samples over a $75 \mathrm{~min}$ period are shown in Fig. 3. It can clearly be seen that there is a marked decrease in the main emission band $(\sim 335 \mathrm{~nm})$ for the ultrasound-treated sample. This is in keeping with other observations using fluorescence to follow the inactivation of PPO (Hemachandran et al., 2017; Sun \& Song, 2003; Xiong et al., 2016). However, there is also a growth in emission of just over $400 \mathrm{~nm}$, which to our knowledge has not previously been reported in this type of experiment. Concomitantly there is the appearance of a shoulder on the shorter wavelength side of the peak emission. The fact that the main emission, which principally emanates from tryptophan, does not change in wavelength is indicative that these fluorophores do not experience any significant change in their microenvironment. Certainly, this emission does not indicate an opening up of the enzyme structure to a more polar (aqueous) environment, which would result in a bathochromic shift. The presence of the shoulder could either relate to tryptophan residues experiencing a less polar environment or to tyrosine emission. The latter would be the result of structural changes causing a decrease in energy transfer from tyrosine to tryptophan, which would also produce a decrease in the intensity of the tryptophan emission. Regardless this shows that ultrasound, rather than a thermal process, has induced changes in the PPO structure, as there is only a small decrease in the main (tryptophan) emission upon thermal treatment (equivalent to $5 \mathrm{~min}$ of ultrasound). There is also no sign of the longer wavelength growth (Fig. 3a). Therefore the growth of the $400 \mathrm{~nm}$ emission can be clearly ascribed to the effect of the ultrasound treatment. The origin of this emission is harder to ascertain but could be the consequence of radical formation caused by the application of ultrasound to the solvent (Islam et al., 2014). The drop in peak fluorescence intensity of the thermally treated pure PPO sample is similar in magnitude to the reduction in residual activity for the equivalent extracted sample after $75 \mathrm{~min}$ 


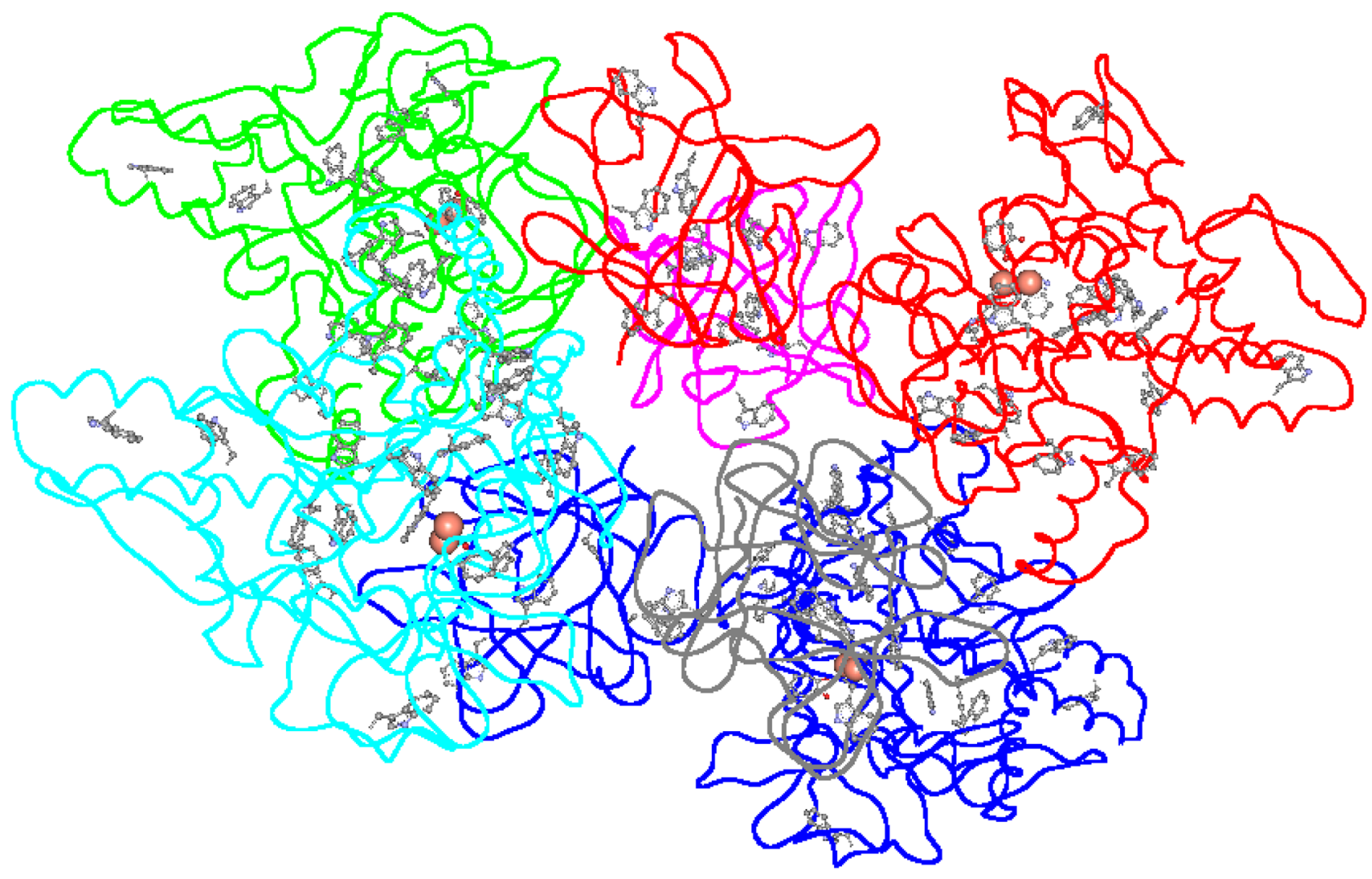

Fig. 2 Cartoon structure of PPO showing the positions of the fluorescent amino acids tyrosine and tryptophan. The structure was downloaded from the RCSB Protein Data Bank (PDB2Y9X) and rendered by molecular modelling using ArgusLab (Plenaria Software)

$(\sim 87 \%)$, and the residual activity data for the pure PPO is also in keeping with that of the extract.

In order to further investigate the correspondence of PPO inactivation with the fluorescence data, a plot of the change in the relative peak intensity (at $335 \mathrm{~nm}$ ) was made (Fig. 3c). This was initially fitted to a Weibull model, but the fit was unsatisfactory and the values obtained $(\gamma=-0.92$, $k=0.091 \mathrm{~min}^{-1}$ ) do not correspond to those of the residual activity data for the extract under equivalent conditions. However, the plot is clearly not linear and can be considered two linear regions (shown), with a transition at $\sim 25 \mathrm{~min}$. In this case, there is approximately a ten times difference $\left(-0.0238 \mathrm{~min}^{-1}\right.$ cf. $\left.-0.0037 \mathrm{~min}^{-1}\right)$ in rate between the two regions, with the rate of the initial decrease in keeping (albeit slightly lower) with that found with the extract. This coincides with the inactivation kinetics fitted using the Weibull model, where the "resistance" of the enzyme causes a slower than expected initial rate of denaturation. Another aspect of this behaviour can relate to the new emission around $400 \mathrm{~nm}$ and the increase of a shorter wavelength shoulder. The growth of the $\sim 400 \mathrm{~nm}$ emission in relation to the main $(335 \mathrm{~nm})$ emission is depicted in Fig. 3d. As in the case of the $335 \mathrm{~nm}$ emission, there is the possibility to consider two linear regions. However, in this case, the transition is around $55 \mathrm{~min}$, with the gradients giving 0.0042 and $0.0138 \mathrm{~min}^{-1}$. At the end of the sonication $(75 \mathrm{~min})$, the peak is $\sim 55 \%$ the intensity of the $335 \mathrm{~nm}$ emission. The fact that an apparently new fluorescent species is forming means that, unlike the thermal data where no ultrasound is applied, there is not the same simple relation between emission intensity and residual activity. There is an apparent two-step process, one dominated by the decrease in the main (tryptophan) emission and another at longer times, forming an emission at $\sim 400 \mathrm{~nm}$, with a concomitant shoulder appearing at shorter wavelengths.

We have recently reported seeing the formation of a longer wavelength emission when horseradish peroxidase is subjected to ultrasound treatment (Tsikrika et al., 2017). This was ascribed to changes in the tyrosine emission, although tempting to use the same explanation here, a further time-resolved investigation was performed discerning the decay-associated spectra in order to try and isolate the different emissions originating from the PPO when excited at $280 \mathrm{~nm}$. This could assist in determining the origin of the emission and hence any structural change occurring in the enzyme, although it is acknowledged that because of the number of fluorophores present, this would be a general description. However, it can still prove useful to elucidate 
(a)

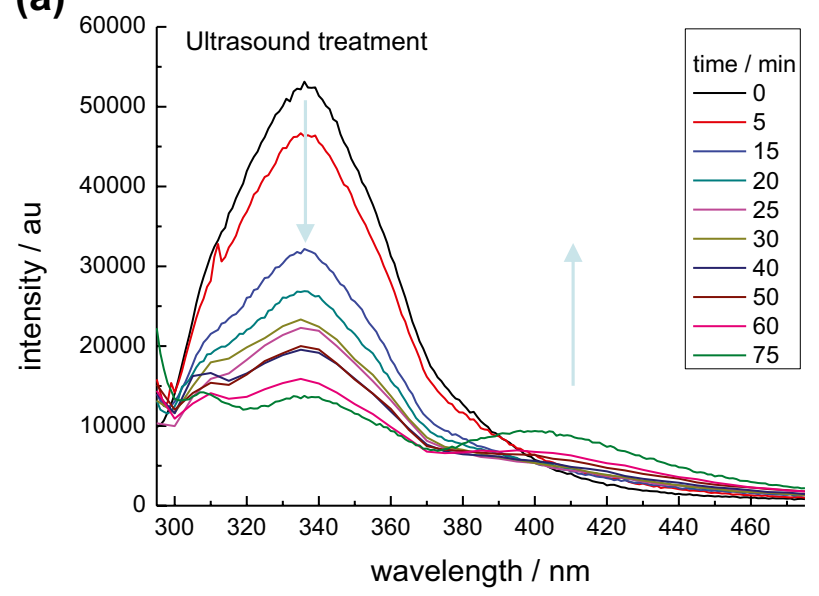

(b)

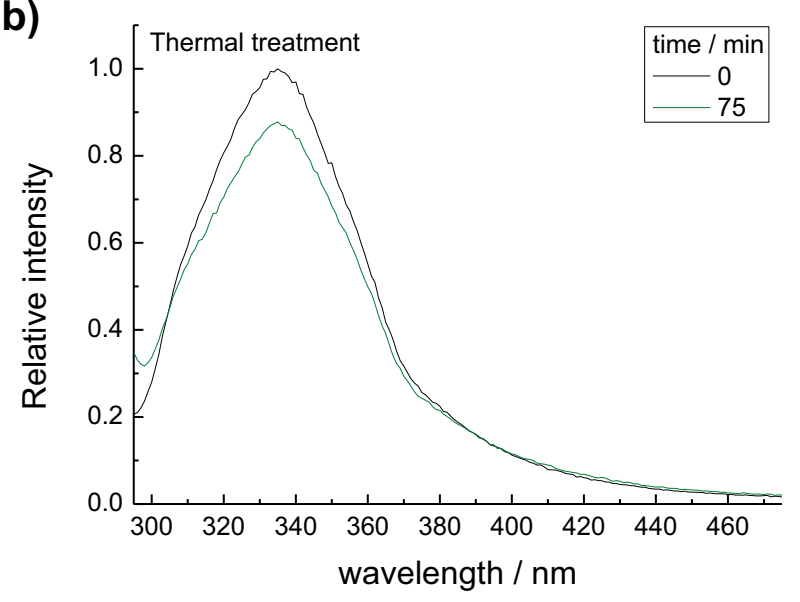

Fig. 3 Steady-state fluorescence from PPO in water excited at $280 \mathrm{~nm}$. a Ultrasound $(583 \mathrm{kHz}, 48 \mathrm{~W})$ treated sample was measured at different times. b Thermally $\left(40{ }^{\circ} \mathrm{C}\right)$ treated sample at the beginning and end of the experiment. $\mathbf{c}$ Change in the relative peak intensity (at $335 \mathrm{~nm}$ ) with the time of sonication at $583 \mathrm{kHz}(48 \mathrm{~W})$. The data is shown fitted using both linear (2 lines) and a Weibull model.

relative changes that can be indicative of the influence of sonication on PPO activity.

The decay-associated spectra, selectively shown in Fig. 4, display the presence of a short-lived component (fixed at 13 ps) which can be tentatively ascribed to Raman scattering from the solvent. Although this can be at a similar wavelength as the emission of tyrosine, the fact that it also coincides with the Raman shift from the solvent and that the strength of this spectrum is more or less constant is indicative of the Raman effect rather than tyrosine as the source of this emission. Thus, for clarity, the shorter-lived associated spectrum is only displayed for the data at the start of the ultrasound treatment. The full spectra are given as Supporting Information. Since there are a reasonable number of fluorescent tryptophan and tyrosine residues in PPO (see Fig. 2), this complicates the interpretation, and the spectral
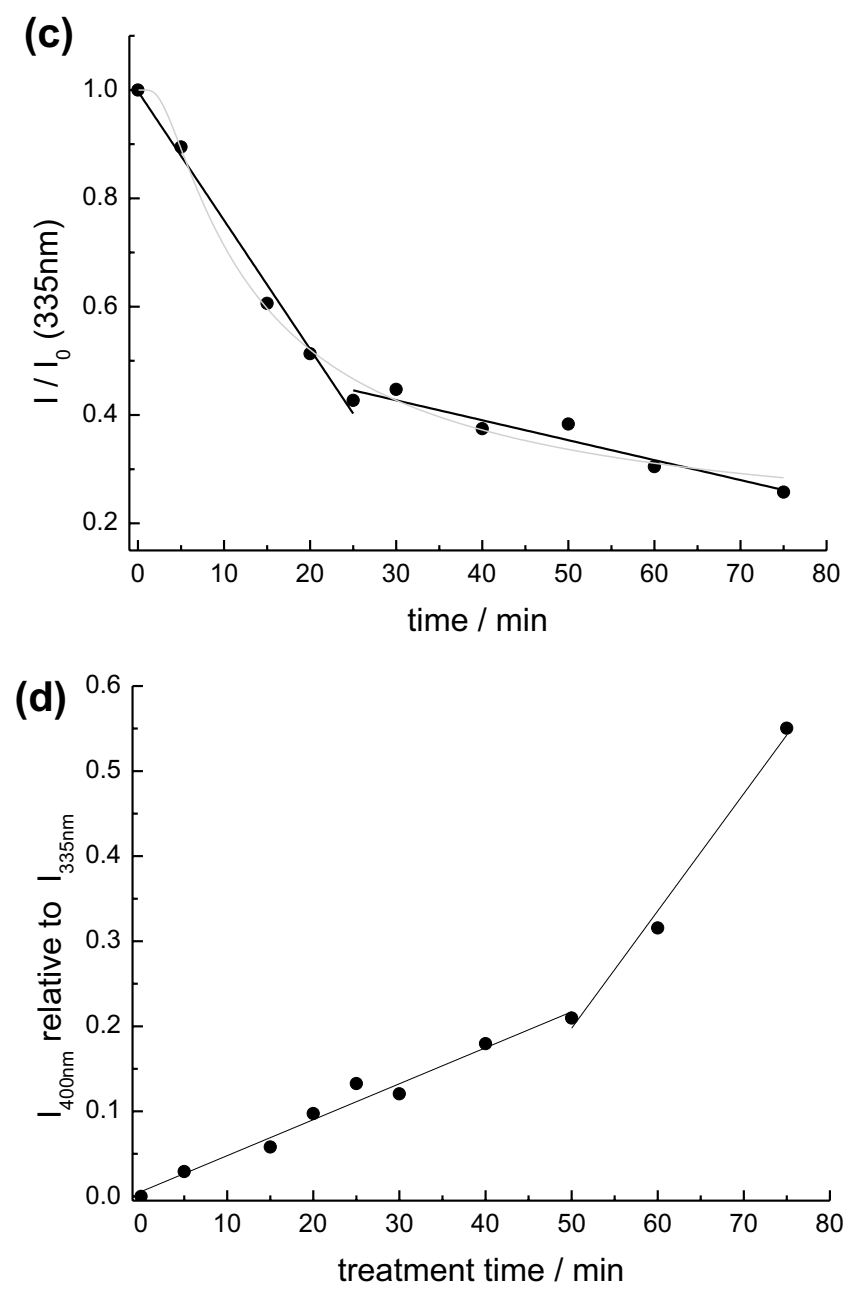

d Intensity in the emission at $400 \mathrm{~nm}$ in relation to the peak intensity $(335 \mathrm{~nm})$. The "background fluorescence" intensity at $400 \mathrm{~nm}$ from the spectrum obtained at the start of the experiment ( 0 min) was corrected by subtracting from the subsequent spectra. The data in two regions were fitted to a linear model

and time-resolved properties will reflect an "average" of the different fluorescing species/environments. However, a relative change in fluorescent behaviour is sufficient for ascertaining if a modification of the PPO is occurring upon ultrasound treatment.

Considering the initial $(0 \mathrm{~min})$ spectra the major contribution to the steady-state emission comes from the spectrum with a peak of $\sim 340 \mathrm{~nm}$ associated with a lifetime of $4.01 \mathrm{~ns}$. Spectra associated with shorter lifetimes exhibit peaks at 337 and $\sim 335 \mathrm{~nm}$ for the 1.69 and $0.382 \mathrm{~ns}$ associated spectra, respectively. The shorter-lived spectrum also displays a shoulder $\sim 315 \mathrm{~nm}$. Although the dominant emission is expected to emanate from tryptophan, a contribution from tyrosine cannot be ruled out, and it should also be noted that a longer wavelength emission $(345 \mathrm{~nm})$ has been reported from potentially ionised tyrosine (Shimizu 

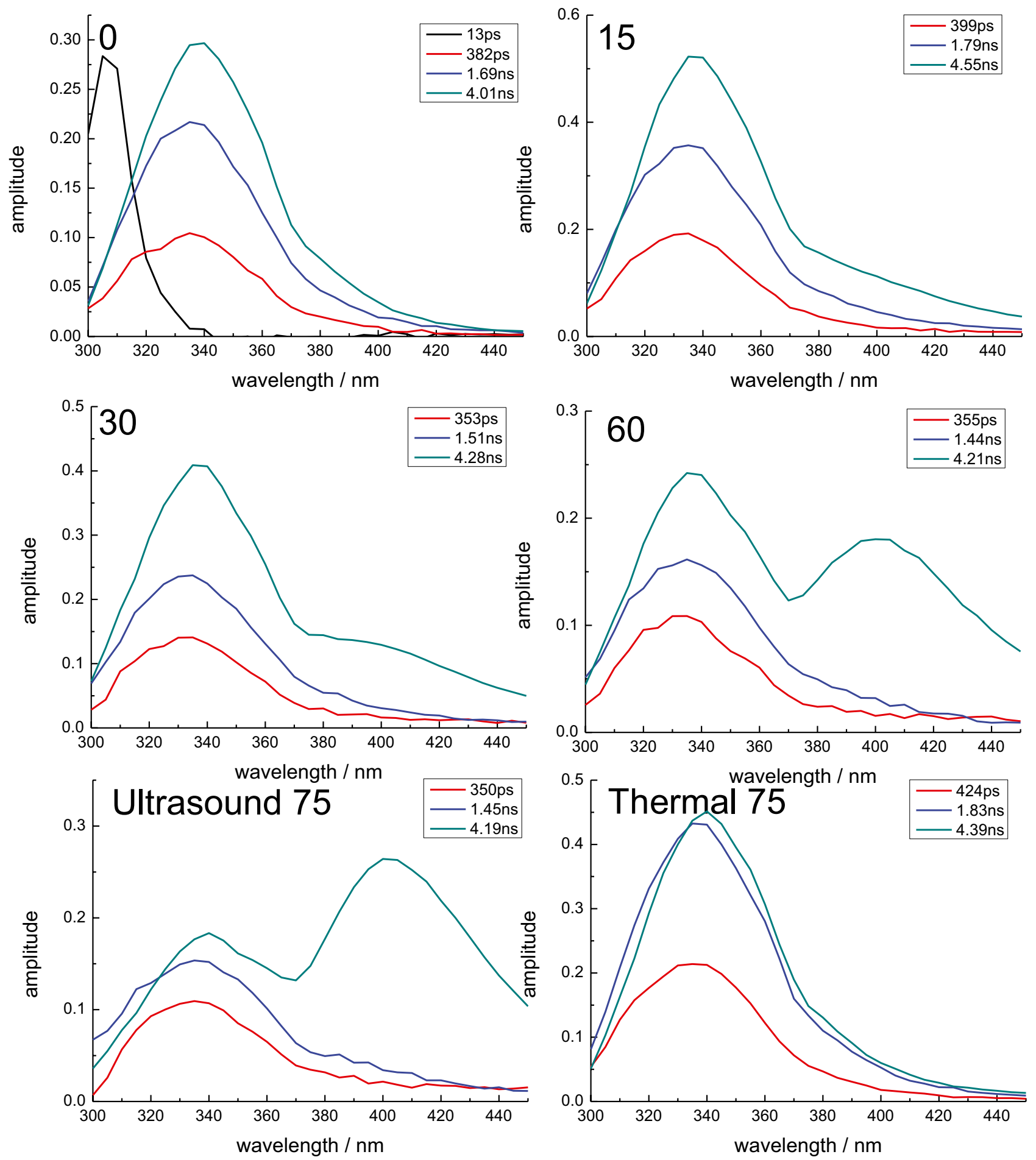

Fig. 4 Decay associated spectra for ultrasound treated PPO at selected times. Apart from the decay-associated spectra at the experiment start (0), the spectrum for the shortest-lived decay, attributed to Raman scattering, has been omitted. The spectra obtained from the

\& Imakubo, 1977), attributed to tyrosinate (Szabo et al., $1978)$ and in DMSO (352 $\mathrm{nm})$ and by extending tyrosine conjugation (Cheruku et al., 2015). However, the latter is unlikely to occur in the initial dataset and, therefore the main thermally treated sample after 75 min of treatment are also given. Times are in minutes, and the full data set can be seen in the supporting information

constituent of the decay associated spectra is expected to be from tryptophan, excited either directly or via energy transfer from the tyrosine. The differences in spectral position then should predominantly relate to differences in the local 
environment since the emission from tryptophan is known to be environmentally sensitive (Lakowicz, 2006; Vivian \& Callis, 2001).

It is clear from Fig. 4 that spectral changes are occurring with ultrasound treatment time. The main feature of these spectra is the growth of emission at $400 \mathrm{~nm}$, as seen in the steady-state data (Fig. 3). This is associated with a lifetime of $\sim 4 \mathrm{~ns}$. The decay-associated spectral data is further summarised in Fig. 5, where the relative contribution of each emission to the overall fluorescence is indicated with ultrasound treatment time. The corresponding fluorescence lifetime is also indicated. It should be remembered that overall there is a decrease in fluorescence emission. The data in Fig. 5 show that the relative contribution of the $\sim 4 \mathrm{~ns}$ emission increases with ultrasound treatment time. This is primarily at the expense of the middle component ( $1.5 \mathrm{~ns})$ emission. The shorter-lived ( $0.4 \mathrm{~ns})$ emission's relative contribution is more or less the same. However, there are notable exceptions at 25 and $50 \mathrm{~min}$. At these treatment times, there is an abrupt increase in the fluorescence lifetime associated with one of the spectra and a change in relative contributions to the emission at those treatment times. These two times coincide with those where the gradient of the linear fit changes in Fig. 3c, d, i.e. the times at which the decrease in the $335 \mathrm{~nm}$ emission lessens and when the growth of the $400 \mathrm{~nm}$ emission increases. The fact that longer ( 8.8 and $11.7 \mathrm{~ns})$ lifetimes arise, linked to the tryptophan emission, is indicative of changes in the local fluorophore environment. This, in turn, can be caused by changes in the enzyme structure.

Thus, several processes appear to be occurring, as evidenced by the fluorescence emission. As well as the

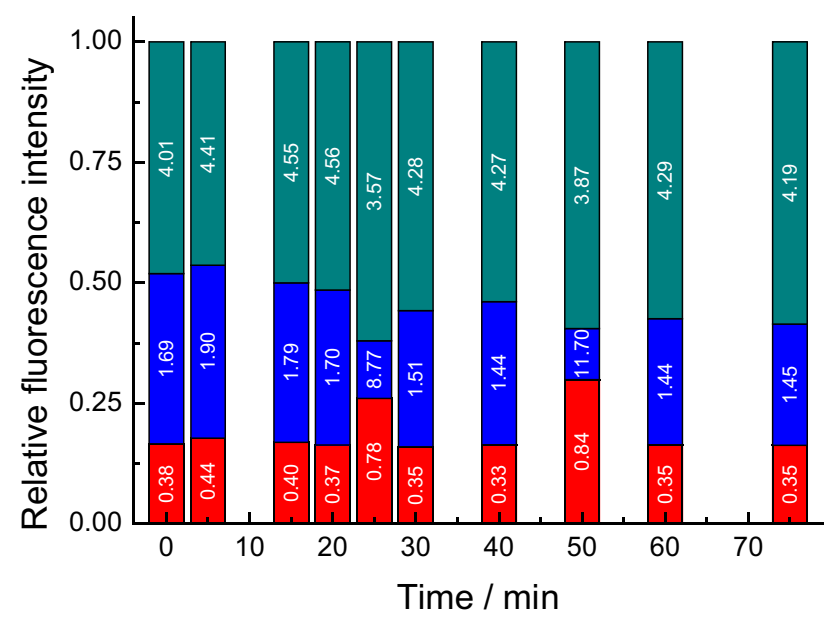

Fig. 5 Analysis from the decay associated spectra for ultrasound treated PPO. The contribution of the relative intensity of the individual spectra to the overall (steady-state) emission is shown normalised. The spectrum associated with the shortest-lived emission has been omitted, and the associated lifetime (in ns) is given denaturation of the PPO, which can simply be followed by the decrease in the principal emission, there is then another process giving rise to a new emission around $400 \mathrm{~nm}$. The latter appears to be induced by the sonication of the solvent (water), which can produce $\mathrm{OH}$ radicals that can interact with the PPO molecule or directly with the fluorophores (principally tyrosine and tryptophan). Changes in solvent access to these moieties could result from an alteration in the PPO structure, enabling radicals formed during the sonication to interact with the fluorophores causing changes in their fluorescent behaviour. However, when considering the longer wavelength emission, tyrosinate emission occurs at too short a wavelength, $345 \mathrm{~nm}$, (Szabo et al., 1978) to explain this. Although increasing the tyrosine conjugation can lengthen the wavelength and di-tyrosine has been reported to emit at 407/408 nm (Huggins et al., 1993; Tang et al., 2006), the other possibility is to consider that the $400 \mathrm{~nm}$ emission originates from changes in the tryptophan. The tryptophan dianion has been reported to emit at $411 \mathrm{~nm}$ (Bridges \& Williams, 1968), and photoproducts have been observed to emit over $400 \mathrm{~nm}$. These photoproducts were postulated to be caused by hydroxylation (Tatischieff et al., 1976) and would certainly be in keeping with $\mathrm{OH}$ radical formation caused by sonication. It is known that tryptophan (and tyrosine) has a low radical reduction potential, and tryptophan radicals can undergo rapid dimerisation (Carroll et al., 2018). Furthermore, emission at $400 \mathrm{~nm}$ has been demonstrated by the photosensitisation of tryptophan and tyrosine derivatives, causing dimerisation (Ludvíková et al., 2018). The exact origin of the $\sim 400 \mathrm{~nm}$ emission is therefore likely to be related to a dimerisation process initiated by the ultrasound treatment. Thus, the fluorescence behaviour can be indicative of the enzyme's residual activity.

\section{Conclusions}

High- and low-frequency ultrasound treatments caused a statistically significant $(p<0.05)$ decrease in mushroom PPO residual activity, while no PPO reactivation was observed after treatment. Complete PPO inactivation was achieved after the application of high-frequency ultrasound at 378 and $578 \mathrm{kHz}$ at a power level of $48 \mathrm{~W}$. Low-frequency ultrasound at $20 \mathrm{kHz}$ and $35 \mathrm{~W}$ resulted in $59 \%$ residual activity after the same length of treatment (90 min). PPO inactivation kinetics data after low-frequency ultrasound treatment at $20 \mathrm{kHz}$ and $35 \mathrm{~W}$ could be described by a first-order model, unlike data at other frequencies, which are better fitted to a Weibull model. The inactivation rate constants were higher after the application of high-frequency ultrasound, while they increased with the use of higher acoustic power within the same frequency. The maximum temperature reached during sonication was $40 \pm 3{ }^{\circ} \mathrm{C}$ hence, a control treatment at 
$40{ }^{\circ} \mathrm{C}$ was performed. PPO activity in the control samples was reduced by only $13 \%$, indicating that PPO inactivation by sonication is attributed to the application of ultrasound rather than any heating effect. Fluorescence analysis in a commercial purified PPO revealed changes in PPO structure occurring at 25 and $50 \mathrm{~min}$ after the application of ultrasound $(583 \mathrm{kHz}, 48 \mathrm{~W})$. A new emission at $400 \mathrm{~nm}$ was observed, which is most likely linked to an ultrasoundinduced dimerisation of the fluorophores. The fluorescence behaviour of the PPO, when excited at $280 \mathrm{~nm}$, can therefore provide information relating to changes induced by the application of ultrasound. Further research is required in order to minimize the inactivation times for PPO as well as to define the specific mechanism of PPO inactivation.

Supplementary Information The online version contains supplementary material available at https://doi.org/10.1007/s11947-022-02777-5.

Acknowledgements The authors would like to thank Abertay R-LINCS for funding this project.

Funding The project was funded by Abertay R-LINCS.

Data Availability All data and materials are available from the authors upon request.

\section{Declarations}

Ethics Approval Not applicable.

Consent to Participate Not applicable.

Consent for Publication Not applicable.

Conflict of Interest The authors declare no competing interests.

Open Access This article is licensed under a Creative Commons Attribution 4.0 International License, which permits use, sharing, adaptation, distribution and reproduction in any medium or format, as long as you give appropriate credit to the original author(s) and the source, provide a link to the Creative Commons licence, and indicate if changes were made. The images or other third party material in this article are included in the article's Creative Commons licence, unless indicated otherwise in a credit line to the material. If material is not included in the article's Creative Commons licence and your intended use is not permitted by statutory regulation or exceeds the permitted use, you will need to obtain permission directly from the copyright holder. To view a copy of this licence, visit http://creativecommons.org/licenses/by/4.0/.

\section{References}

Abid, M., Jabbar, S., Hu, B., Hashim, M. M., Wu, T., Wu, Z., et al. (2014). Synergistic impact of sonication and high hydrostatic pressure on microbial and enzymatic inactivation of apple juice. LWT - Food Science and Technology, 59(1), 70-76. https://doi. org/10.1016/j.lwt.2014.04.039
Baltacığlu, H., Bayındırlı, A., \& Severcan, F. (2017). Secondary structure and conformational change of mushroom polyphenol oxidase during thermosonication treatment by using FTIR spectroscopy. Food Chemistry, 214, 507-514. https://doi.org/10. 1016/j.foodchem.2016.07.021

Bhargava, N., Mor, R. S., Kumar, K., \& Sharanagat, V. S. (2021). Advances in application of ultrasound in food processing: A review. Ultrasonics Sonochemistry, 70, 105293. https://doi.org/ 10.1016/J.ULTSONCH.2020.105293

Bi, X., Hemar, Y., Balaban, M. O., \& Liao, X. (2015). The effect of ultrasound on particle size, color, viscosity and polyphenol oxidase activity of diluted avocado puree. Ultrasonics Sonochemistry. https://doi.org/10.1016/j.ultsonch.2015.04.011

Birch, D. J., \& Imhof, R. E. (1991). Time-domain fluorescence spectroscopy using time-correlated single photon counting. TechniquesIn J. R. Lakowicz (Ed.), Topics in Fluorescence Spectroscopy (Vol. 1, pp. 1-95). Plenum Press.

Bridges, J. W., \& Williams, R. T. (1968). The fluorescence of indoles and aniline derivatives. Biochemical Journal, 107, 225-237.

Buckow, R., Weiss, U., \& Knorr, D. (2009). Inactivation kinetics of apple polyphenol oxidase in different pressure-temperature domains. Innovative Food Science \& Emerging Technologies, 10(4), 441-448. https://doi.org/10.1016/J.IFSET.2009.05.005

Cao, X., Cai, C., Wang, Y., \& Zheng, X. (2018). The inactivation kinetics of polyphenol oxidase and peroxidase in bayberry juice during thermal and ultrasound treatments. Innovative Food Science \& Emerging Technologies, 45, 169-178. https://doi.org/10. 1016/J.IFSET.2017.09.018

Carroll, L., Pattison, D. I., Davies, J. B., Anderson, R. F., LopezAlarcon, C., \& Davies, M. J. (2018). Superoxide radicals react with peptide-derived tryptophan radicals with very high rate constants to give hydroperoxides as major products. Free Radical Biology and Medicine, 118, 123-136. https://doi.org/10. 1016/j.freeradbiomed.2018.02.033

Chemat, F., e-Huma, Z., \& Khan, M. K. (2011). Applications of ultrasound in food technology: Processing, preservation and extraction. Ultrasonics Sonochemistry, 18(4), 813-835. https:// doi.org/10.1016/j.ultsonch.2010.11.023

Chemat, F., Rombaut, N., Meullemiestre, A., Turk, M., Perino, S., Fabiano-Tixier, A. S., \& Abert-Vian, M. (2017). Review of green food processing techniques. Preservation, transformation, and extraction. Innovative Food Science and Emerging Technologies, 41, 357-377. https://doi.org/10.1016/j.ifset.2017.04.016

Cheng, X., Zhang, M., \& Adhikari, B. (2013). The inactivation kinetics of polyphenol oxidase in mushroom (Agaricus bisporus) during thermal and thermosonic treatments. Ultrasonics Sonochemistry, 20(2), 674-679. https://doi.org/10.1016/j.ultsonch. 2012.09.012

Cheruku, P., Huang, J. -H., Yen, H. -J., Iyer, R. S., Rector, K. D., Martinez, J. S., \& Wang, H.-L. (2015). Tyrosine-derived stimuli responsive, fluorescent amino acids. Chemical Science, 6 , $1150-1158$

Dias, D. D. R. C., Barros, Z. M. P., De Carvalho, C. B. O., Honorato, F. A., Guerra, N. B., \& Azoubel, P. M. (2014). Effect of sonication on soursop juice quality. LWT - Food Science and Technology. https://doi.org/10.1016/j.lwt.2014.09.043

Elez-Martínez, P., Aguiló-Aguayo, I., \& Martín-Belloso, O. (2006). Inactivation of orange juice peroxidase by high-intensity pulsed electric fields as influenced by process parameters. Journal of the Science of Food and Agriculture, 86(1), 71-81. https://doi.org/ $10.1002 /$ jsfa.2306

Fortea, M. I., López-Miranda, S., Serrano-Martínez, A., Carreño, J., \& Núñez-Delicado, E. (2009). Kinetic characterisation and thermal inactivation study of polyphenol oxidase and peroxidase from table grape (Crimson Seedless). Food Chemistry, 113(4), 10081014. https://doi.org/10.1016/j.foodchem.2008.08.053 
Giner, J., Grouberman, P., Gimeno, V., \& Martín, O. (2005). Reduction of pectinesterase activity in a commercial enzyme preparation by pulsed electric fields: Comparison of inactivation kinetic models. Journal of the Science of Food and Agriculture, 85(10), 1613-1621. https://doi.org/10.1002/jsfa.2154

Hemachandran, H., Anantharaman, A., Mohan, S., Mohan, G., Kumar, D. T., Dey, D., et al. (2017). Unraveling the inhibition mechanism of cyanidin-3-sophoroside on polyphenol oxidase and its effect on enzymatic browning of apples. Food Chemistry, 227, 102-110. https://doi.org/10.1016/j.foodchem.2017.01.041

Huggins, T. G., Wells-Knecht, M. C., Detorie, N. A., Baynes, J. W., \& Thorpe, S. R. (1993). Formation of o-tyrosine and dityrosine in proteins during radiolytic and metal-catalyzed oxidation. Journal of Biological Chemistry, 268(17), 12341-12347. http://www.jbc. org/cgi/content/short/268/17/12341. Accessed 1 Jun 2018.

Illera, A. E., Sanz, M. T., Benito-Román, O., Varona, S., Beltrán, S., Melgosa, R., \& Solaesa, A. G. (2018). Effect of thermosonication batch treatment on enzyme inactivation kinetics and other quality parameters of cloudy apple juice. Innovative Food Science and Emerging Technologies, 47(2017), 71-80. https://doi.org/10. 1016/j.ifset.2018.02.001

Iqbal, A., Murtaza, A., Marszałek, K., Iqbal, M. A., Chughtai, M. F. J., Hu, W., et al. (2020). Inactivation and structural changes of polyphenol oxidase in quince (Cydonia oblonga Miller) juice subjected to ultrasonic treatment. Journal of the Science of Food and Agriculture. https://doi.org/10.1002/jsfa.10229

Islam, M. N., Zhang, M., Adhikari, B., Xinfeng, C., \& Xu, B. (2014). The effect of ultrasound-assisted immersion freezing on selected physicochemical properties of mushrooms. International Journal of Refrigeration, 42, 121-133. https://doi.org/10.1016/j.ijrefrig. 2014.02.012

Ismaya, W. T., Rozeboom, H. J., Weijn, A., Mes, J. J., Fusetti, F., Wichers, H. J., \& Dijkstra, B. W. (2011). Crystal structure of agaricus bisporus mushroom tyrosinase: Identity of the tetramer subunits and interaction with tropolone. Biochemistry, 50(24), 5477-5486. https://doi. org/10.1021/bi200395t

Jaramillo Sánchez, G. M., Garcia Loredo, A. B., Contigiani, E. V., Gómez, P. L., \& Alzamora, S. M. (2018). Inactivation kinetics of peroxidase and polyphenol oxidase in peach juice treated with gaseous ozone. International Journal of Food Science and Technology, 53(2), 347-355. https://doi.org/10.1111/ijfs.13591

Lakowicz, J. R. (2006). Principles of fluorescence spectroscopy. Principles of fluorescence spectroscopy (3rd ed.). New York, NY: Springer New York. https://doi.org/10.1007/978-0-387-46312-4

Lemos, M. A., \& Hungerford, G. (2013). The binding of Curcuma longa extract with bovine serum albumin monitored via timeresolved fluorescence. Photochemistry and Photobiology, 89(5), 1071-1078. https://doi.org/10.1111/php.12129

Liu, S., Liu, Y., Huang, X., Yang, W., Hu, W., \& Pan, S. (2017). Effect of ultrasonic processing on the changes in activity, aggregation and the secondary and tertiary structure of polyphenol oxidase in oriental sweet melon (Cucumis melo var. makuwa Makino). Journal of the Science of Food and Agriculture, 97(4), 1326-1334. https://doi.org/10.1002/jsfa.7869

Ludikhuyze, L., Van Loey, A., Indrawati, Smout, C., \& Hendrickx, M. (2003). Effects of combined pressure and temperature on enzymes related to quality of fruits and vegetables: From kinetic information to process engineering aspects. Critical Reviews in Food Science and Nutrition, 43. https://doi.org/10.1080/10408690390246350

Ludvíková, L., Štacko, P., Sperry, J., \& Klán, P. (2018). Photosensitized cross-linking of tryptophan and derivatives by rose bengal in aqueous solutions. The Journal of Organic Chemistry, 83(18), 10835-10844. https://doi.org/10.1021/acs.joc.8b01545

Milne, L., Stewart, I., \& Bremner, D. H. (2013). Comparison of hydroxyl radical formation in aqueous solutions at different ultrasound frequencies and powers using the salicylic acid dosimeter.
Ultrasonics Sonochemistry, 20(3), 984-989. https://doi.org/10. 1016/j.ultsonch.2012.10.020

Morales-de la Peña, M., Welti-Chanes, J., \& Martín-Belloso, O. (2019). Novel technologies to improve food safety and quality. Current Opinion in Food Science, 30, 1-7. https://doi.org/10.1016/j.cofs.2018.10.009

Pingret, D., Fabiano-Tixier, A. -S., \& Chemat, F. (2013). Degradation during application of ultrasound in food processing: A review. Food Control, 31(2), 593-606. https://doi.org/10.1016/j.foodcont.2012.11.039

Quintão-Teixeira, L. J., Soliva-Fortuny, R., Mota Ramos, A., \& MartínBelloso, O. (2013). Kinetics of peroxidase inactivation in carrot juice treated with pulsed electric fields. Journal of Food Science. https://doi.org/10.1111/1750-3841.12019

Raviyan, P., Zhang, Z., \& Feng, H. (2005). Ultrasonication for tomato pectinmethylesterase inactivation: Effect of cavitation intensity and temperature on inactivation. Journal of Food Engineering, 70(2), 189-196. https://doi.org/10.1016/j. jfoodeng.2004.09.028

Rojas, M. L., Trevilin, J. H., dos Santos Funcia, E., Gut, J. A. W., \& Augusto, P. E. D. (2017). Using ultrasound technology for the inactivation and thermal sensitization of peroxidase in green coconut water. Ultrasonics Sonochemistry, 36, 173-181. https://doi. org/10.1016/J.ULTSONCH.2016.11.028

Saeeduddin, M., Abid, M., Jabbar, S., Wu, T., Hashim, M. M., Awad, F. N., et al. (2015). Quality assessment of pear juice under ultrasound and commercial pasteurization processing conditions. LWT - Food Science and Technology, 64(1), 452-458. https://doi.org/ 10.1016/j.lwt.2015.05.005

Shimizu, O., \& Imakubo, K. (1977). New emission of tyrosine induced by the interaction with phosphate ion. Phochemistry and Photobiology, 26, 541-543.

Shinwari, K. J., \& Rao, P. S. (2018). Stability of bioactive compounds in fruit jam and jelly during processing and storage: A review. Trends in Food Science \& Technology, 75, 181-193. https://doi. org/10.1016/J.TIFS.2018.02.002

Shinwari, K. J., \& Rao, P. S. (2021). Enzyme inactivation and its kinetics in a reduced-calorie sapodilla (Manilkara zapota L.) jam processed by thermal-assisted high hydrostatic pressure. Food and Bioproducts Processing, 126, 305-316. https://doi.org/10.1016/J. FBP.2021.01.013

Silva, F. V. M., \& Sulaiman, A. (2018). Polyphenoloxidase in fruit and vegetables: Inactivation by thermal and non-thermal processes. Elsevier. https://doi.org/10.1016/B978-0-08-100596-5.21636-3

Soliva-Fortuny, R., Bendicho-Porta, S., \& Martín-Belloso, O. (2006). Modeling high-intensity pulsed electric field inactivation of a lipase from pseudomonas fluorescens. Journal of Dairy Science, 89(11), 4096-4104. https://doi.org/10.3168/JDS.S0022-0302(06)72455-9

Sulaiman, A., Soo, M. J., Farid, M., \& Silva, F. V. M. (2015a). Thermosonication for polyphenoloxidase inactivation in fruits: Modeling the ultrasound and thermal kinetics in pear, apple and strawberry purees at different temperatures. Journal of Food Engineering, 165, 133-140. https://doi.org/10.1016/j.jfoodeng.2015.06.020

Sulaiman, A., Soo, M. J., Yoon, M. M. L., Farid, M., \& Silva, F. V. M. (2015b). Modeling the polyphenoloxidase inactivation kinetics in pear, apple and strawberry purees after high pressure processing. Journal of Food Engineering, 147, 89-94. https://doi.org/10. 1016/J.JFOODENG.2014.09.030

Sun, N. K., \& Song, K. B. (2003). Effect of nonthermal treatment on the molecular properties of mushroom polyphenoloxidase. Journal of Food Science, 68(5), 1639-1643. https://doi.org/10.1111/j. 1365-2621.2003.tb12305.x

Szabo, A. G., Lynn, K. R., Krajcarski, D. T., \& Rayner, D. M. (1978). Tyrosinate fluorescence maxima at $345 \mathrm{~nm}$ in proteins lacking tryptophan at $\mathrm{pH}$ 7'. FEBS Letters, 94, 249-252.

Tang, B., Wang, Y., Liang, H., Chen, Z., He, X., \& Shen, H. (2006). Studies on the oxidation reaction of tyrosine (Tyr) with $\mathrm{H} 2 \mathrm{O} 2$ catalyzed by horseradish peroxidase (HRP) in alcohol-water medium 
by spectrofluorimetry and differential spectrophotometry. Spectrochimica Acta Part A: Molecular and Biomolecular Spectroscopy, 63(3), 609-613. https://doi.org/10.1016/J.SAA.2005.06.008

Tatischieff, I., Klein, R., \& Duquesne, M. (1976). A new fluorescent photoproduct of tryptophan evidenced by long wavelength excitation of fluorescence. Photochemistry and Photobiology, 24, 413-416.

Tian, Z. M., Wan, M. X., Wang, S. P., \& Kang, J. Q. (2004). Effects of ultrasound and additives on the function and structure of trypsin. Ultrasonics Sonochemistry, 11(6), 399-404. https://doi.org/10. 1016/j.ultsonch.2003.09.004

Tsikrika, K., Chu, B. S., Bremner, D. H., \& Lemos, M. A. (2018). The effect of different frequencies of ultrasound on the activity of horseradish peroxidase. LWT - Food Science and Technology, 89, 591-595. https://doi.org/10.1016/j.1wt.2017.11.021

Tsikrika, K., Lemos, M. A., Chu, B. S., Bremner, D. H., \& Hungerford, G. (2017). Time-resolved fluorescence observation of di-tyrosine formation in horseradish peroxidase upon ultrasound treatment leading to enzyme inactivation. Spectrochimica Acta - Part A: Molecular and Biomolecular Spectroscopy, 173, 324-327. https:// doi.org/10.1016/j.saa.2016.09.035
Vivian, J. T., \& Callis, P. R. (2001). Mechanisms of tryptophan fluorescence shifts in proteins. Biophysical Journal, 80, 2093-2109.

Xiong, Z., Liu, W., Zhou, L., Zou, L., \& Chen, J. (2016). Mushroom (Agaricus bisporus) polyphenoloxidase inhibited by apigenin: Multi-spectroscopic analyses and computational docking simulation. Food Chemistry, 203, 430-439. https://doi.org/10.1016/j. foodchem.2016.02.045

Yu, Z. -L., Zeng, W. -C., \& Lu, X. -L. (2013). Influence of ultrasound to the activity of tyrosinase. Ultrasonics Sonochemistry, 20(3), 805-809. https://doi.org/10.1016/j.ultsonch.2012.11.006

Zhu, L., Zhu, L., Murtaza, A., Liu, Y., Liu, S., Li, J., et al. (2019). Ultrasonic processing induced activity and structural changes of polyphenol oxidase in orange (Citrus sinensis Osbeck). Molecules, 24(10), 1922. https://doi.org/10.3390/molecules 24101922

Publisher's Note Springer Nature remains neutral with regard to jurisdictional claims in published maps and institutional affiliations. 